\title{
Mathematical data processing according to digital image correlation method for polymer composites
}

\author{
Elena M. Strungar, Dmitrii S. Lobanov \\ Perm National Research Polytechnic University, Russia \\ cem.spaskova@mail.ru, bttp://orcid.org/0000-0002-2246-8638 \\ cem.lobanov@gmail.com, bttp: / /orcid.org/0000-0003-1948-436X
}

\begin{abstract}
The paper analyses the numerical algorithms for experimental data processing using a contactless video system Vic-3D, designed for threedimension analysis of displacement and strain fields, and digital image correlation method. The authors considered methodological issues of conducting an experiment using a video system. They suggested recommendations on the choice of parameters of calculation of correlation, the size of subset and step during the analysis of non-homogeneous displacement and strain fields in polymer composite materials through laminated fiberglass composite. The efficient parameters of mathematical data processing are identified according to digital image correlation method on the basis of building fields for one frame on the surface of laminated fiberglass reinforced plastic at various subset values and at fixed step value. The paper shows the impact of step value on the strain fields detail degree. The authors have identified the relation of the chosen parameters of experimental data processing using digital image correlation method with the scaled levels of consideration of composite materials strain processes. To evaluate the strains at various scale levels, the paper uses supplementary video system instruments: "virtual extensometer", "rectangular area" and "line". The authors obtained a longitudinal strain profile that allows evaluating the location of strain peak areas on the composite object surface.
\end{abstract}

KEYwORDS. The method of digital image correlation; Composite material; Scale level; Mathematical parameters of correlation analysis; Structurally heterogeneous material.

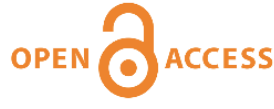

Citation: Strungar, E. M., Lobanov, D. S. Mathematical data processing according to digital image correlation method for polymer composites, Frattura ed Integrità Strutturale, 54 (2020) 56-65.

Received: 02.06 .2020

Accepted: 29.06 .2020 Published: 01.10 .2020

Copyright: (C) 2020 This is an open access article under the terms of the CC-BY 4.0, which permits unrestricted use, distribution, and reproduction in any medium, provided the original author and source are credited.

\section{INTRODUCTION}

$\mathrm{D}$ ue to high specific physical-mechanical properties the polymer composites are widely used in all fields of aviation and automobile industry, power industry and machine building which provides a number of benefits as compared to metals [1-5]. Experimentally proven correlation between micro- and macroscales in composite 
materials is of special importance because it provides the establishment of true multiscale structure during the composite materials study. Composite materials possess significant structural non-homogeneity, besides, scientific literature points out the structure complexity, therefore, the defects should be considered at various levels and stages of manufacture of components, materials and products $[1,6,7]$.

Multiscale structures can bring the most efficient and realistic models, which, in turn, will improve understanding of mechanical behavior of composite materials. The approaches based on experimental studies, that show the relation of strain measurement on the reinforcing element strain level with the macroscale material response are poorly reflected in scientific literature. It is necessary to study the complex interactions between the reinforcing fibers and the matrix, homogenization algorithms should be performed at carefully selected volume (or surface) of material which is low enough to cover the impact of each individual component and at the same time large enough to represent the global response of the material [8-13].

Such promising methods as ultrasonic testing, X-ray tomography, thermography, acoustic emission (AE), fiber-optic methods etc. are used to study the defects, fissures, delaminations that occur in composite materials [6,7,14-18]. A prospective trend of experimental mechanics is the simultaneous use of the methods presented.

Contactless optical methods are widely used to analyze the stress-strained condition of the deformed elements of composite structures with significant structural non-homogeneity in the process of mechanical properties study. The digital images correlation (DIC) method is one of the prospective experimental methods of displacement and strain fields study. The development of a new method for solution of tasks of deformed solids mechanics calls for complex studies of the efficacy of using this experimental mechanics "instrument" as applied to the analysis of mechanical behavior of solids of various structures at implementation of complex modes of external exposures. Nevertheless, there are some problems related to the use of DIC at small scales for essentially structurally non-homogeneous materials [12, 19].

To evaluate the structural features of material, to study the processes of origination and development of defect structures and destructions using DIC method, special attention should be paid to the selection of correlation processing parameters, in particular, the choice of subset size and step value [15]. The main objective of the paper is the analysis of specific features of testing process using the digital optical system, and substantiation of the choice of efficient parameters of data processing using DIC method as applied to composite materials objects.

\section{METHODOLOGY AND METHODS OF RESEARCH}

$\mathrm{D}$ igital image correlation method is a contactless optical method for recording the displacement and strain fields on the object surface. All information is contained in the structure (pixel distribution) on the surface of the test object with varying degrees of brightness of black-and-white image. During digital images processing by DIC method, displacement vectors are calculated not at each individual image point (in the pixel), but by discretizing the study area into small local subsets, or, in other words, correlation areas $X \times X$ pixels in size (Fig. 1). The subset size significantly affects the accuracy of correlation analysis, the degree of detail of displacement and strain fields along the surface of the studied object, as well as the size of the edge zone that occurs on the edge or near the stress concentrators (holes, inclusions, fissures, defects). The step value sets the distance between the points (central pixels of the subset) analyzed during the mathematical processing in pixels.

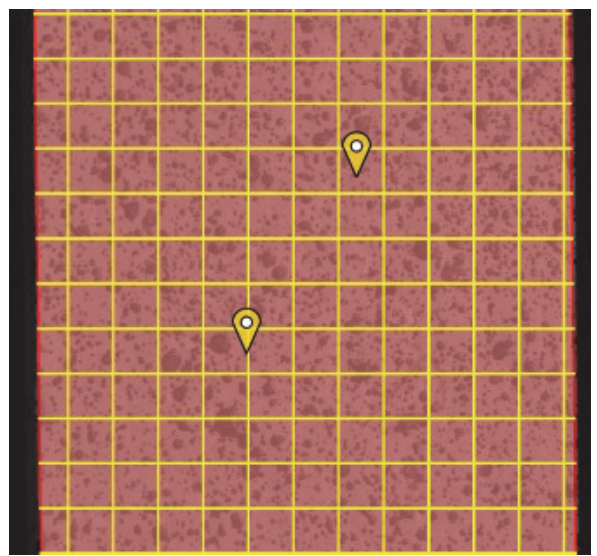

Figure 1: Discretization of the area of study into subsets. 
The choice of the subset value $X$ and step $\Delta X$ depends on the conditions of the shooting performed, the results of the video system calibration, as well as on the geometric parameters of the study object and the structural features of the sample material. Even under almost perfect experimental conditions, the differences between the intensities of images recorded at different times will exist. These changes can be caused by various reasons, for example, changes in lighting, changes in the sample reflectivity due to deformation, or changes in the sample orientation. The procedure of identification of the image sections is carried out by calculating the coefficient of correspondence of images and the search for its minimum.

In this paper, we use the criterion of the normalized sum of squared differences with a zero mean, because it is the least sensitive to changes in lighting during the test. The subset value is acceptable if the value of the correlation coefficient does not exceed $A \leq 0.01$. In scientific literature [19], the correlation coefficient value is indicated as $\sigma$; in this paper, we changed the indication into " $\mathrm{A}$ " to avoid misinterpretation of the well-known stress indication.

In the course of post-processing by Vic-3D system, the deformation components were calculated in this paper using the finite strain tensor in the sense of Lagrange [19].

The software Vic-3D provides the recording of strain using a video system instrument "virtual extensometer". The principle of its action is similar to resistance strain gauge, it consists in tracking the mutual displacement between two points of the surface of the samples according to the applied force. The main advantages of the use of the "virtual extensometer" are the contactless registration of deformations, which eliminates mechanical impact on the surface of the sample.

In addition, additional video system tools were used in the work: the "rectangular region" and "line" to determine the average deformations in the region and along the averaging line, respectively. To implement the tool "rectangular area" in the working area of the sample area was allocated in the form of a rectangle. The line tool is a line drawn on the surface of the sample along which strain averaging occurs. It is worth noting that the strain assessment is carried out already at the post-processing stage by the specialized Vic-3D program, after the test.

\section{EQUIPMENT, TECHNIQUE AND MATERIAL}

$\mathrm{E}$ xperimental studies were carried out using the large-scale research facilities «Complex of testing and diagnostic equipment for studying properties of structural and functional materials under complex thermomechanical loading» PNRPU modernized with funds by the Ministry of Science and Higher Education of the Russian Federation, Unique project identifier RFMEFI61920X0017.

The uniaxial tensile of a structural fiberglass specimen will be considered as an example of digital image processing using DIC method. Experimental studies were conducted at an electromechanical system Instron 5989 at normal temperature. The movable grip speed was $2 \mathrm{~mm} / \mathrm{min}$. The deformations on the surface of the samples were recorded using the Vic-3D contactless optical video system and DIC method. The video system preciseness was determined by technical characteristics of objectives and digital cameras, in particular, matrix sensibility, resolving power and the possible framing frequency. The strain process video recording was performed using cameras with $35 \mathrm{~mm}$ objective. The shooting speed was 3 frames per second with the set cameras resolution of 16.0 MP. The optical recording systems synchronization with the test system controllers in the process of testing was provided by analog-to-digital converter unit (NI USB-6251) (Fig. 2).

The strain experiments were performed in compliance with ASTM D3039 recommendations using strip samples $25 \mathrm{~mm}$ wide, $5 \mathrm{~mm}$ thick with $120 \mathrm{~mm}$ working part. The material used in the study is the general purpose construction fiberglass laminate STEF. It is laminated reinforced fiberglass obtained by hot pressing of fiberglass cloth impregnated with thermoreactive compound based on combined epoxide and phenolformaldehyde resins. Fig. 3. (a) presents the image of a composite sample surface with a marked structural element $\delta$, obtained using a stereomicroscope Carl Zeiss SteREO Discovery V12. The size of the structural element $\delta$ means the width of interlacing cell, for this material it is $\delta=4 \mathrm{~mm}$.

To implement DIC method, a finely dispersed coating should be applied on the surface before testing, prior to the object stressing (Fig. 3. (b)). The coating provides reliable identification of displacements and improves the fine detail resolution of the surface studied. There are various methods of application of such coating, for example, with laser speckles [20]. In this study the black and white dots were applied on the specimen surface by means of aerosol paint.

The finely dispersed coating significantly affects the image correlation preciseness which is reflected in the paper [21]. Numerous recommendations on application of the coating were taken into account in this study [22], they were not analyzed separately. 


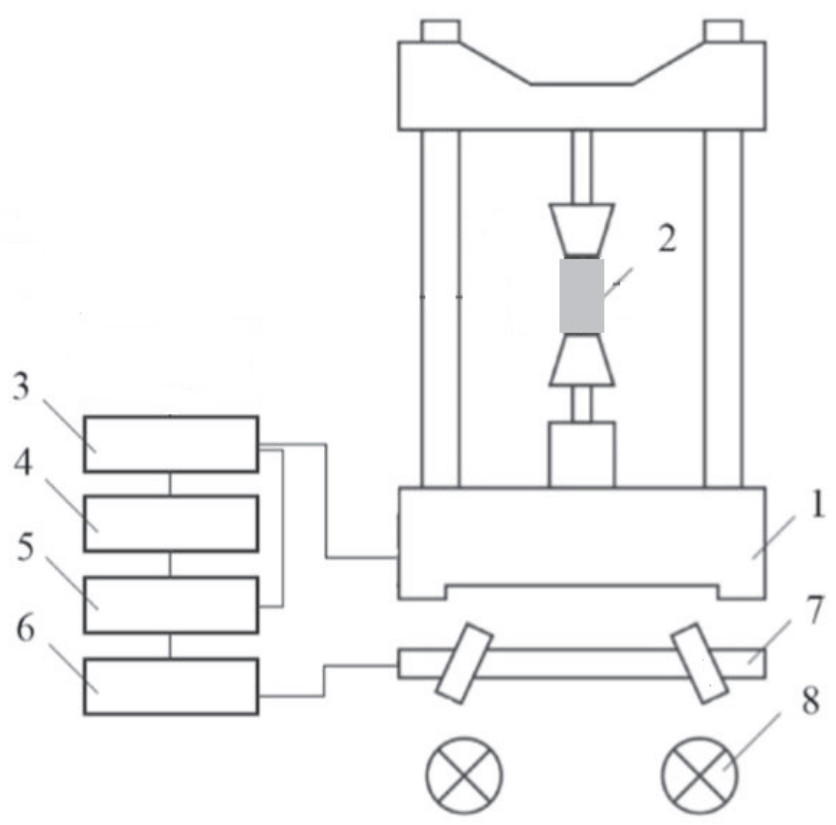

Figure 2: Test pattern together with the non-contact optical video system and the acoustic emission recording system: 1 -test machine, 2-specimen installed in the grips, 3-test system controller, 4-PC from which the machine is controlled, 5synchronization unit, 6- PC from which the video system is controlled, 7-cameras mounted on the support, 8-lighting system.

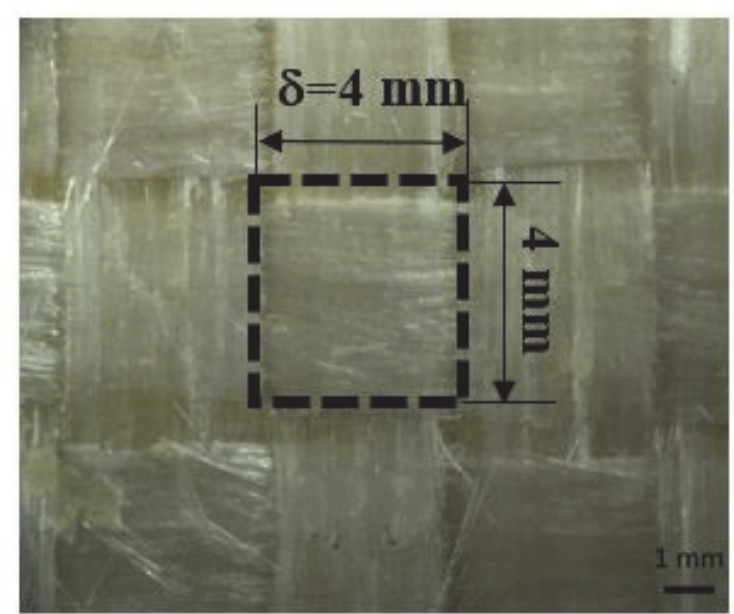

a

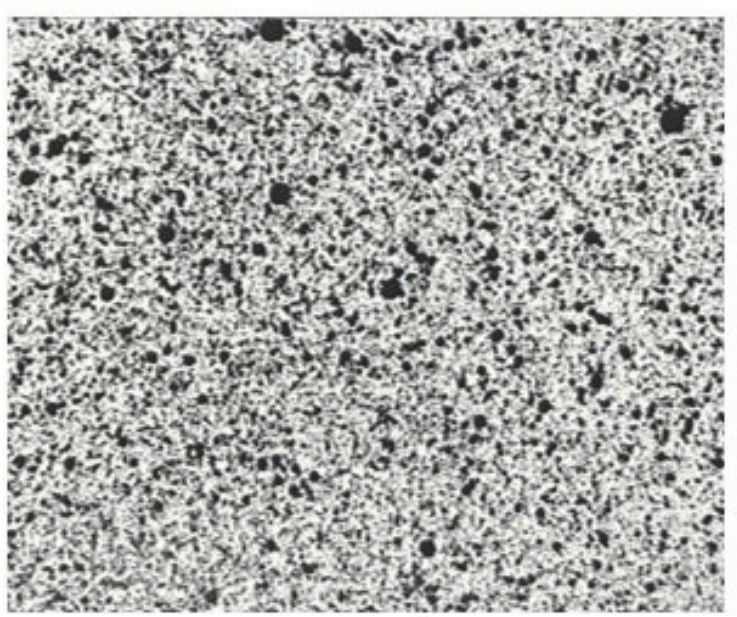

b

Figure 3: The image of the specimen before (a) and after (b) application of contrast finely dispersed coating on its surface.

\section{METHODICAL PROBLEMS OF DATA PROCESSING USING DIGITAL IMAGE CORRELATION METHOD}

o evaluate the effect of correlation processing parameters on non-homogeneous strain fields, the authors conducted a series of construction of fields for one frame on the surface of laminated reinforced fiberglass at various values of subset and the interval of $X=35 \div 63$ and at fixed step value $\Delta X=3$ pixels. The results are provided in Tab. 1, where maximal $A_{\text {max }}$, average $A_{\text {mean }}$ and minimal correlation $A_{\text {min }}$ coefficient values are presented. 


\begin{tabular}{|c|c|c|c|c|c|c|c|}
\hline Х, П & $\mathrm{A}_{\text {mean }}$ & $\mathrm{A}_{\max }$ & $\mathrm{A}_{\min }$ & Х, П & $\mathrm{A}_{\text {mean }}$ & $\mathrm{A}_{\max }$ & $\mathrm{A}_{\min }$ \\
\hline 35 & 0.0040 & 0.0194 & 0.0015 & 51 & 0.0026 & 0.0108 & 0.0012 \\
\hline 39 & 0.0035 & 0.0169 & 0.0014 & 53 & 0.0025 & 0.0100 & 0.0012 \\
\hline 43 & 0.0031 & 0.0148 & 0.0014 & 55 & 0.0024 & 0.0093 & 0.0012 \\
\hline 45 & 0.0030 & 0.0137 & 0.0013 & 57 & 0.0023 & 0.0087 & 0.0011 \\
\hline 47 & 0.0028 & 0.0126 & 0.0013 & 59 & 0.0022 & 0.0081 & 0.0011 \\
\hline 49 & 0.0027 & 0.0117 & 0.0013 & 63 & 0.0021 & 0.0071 & 0.0011 \\
\hline
\end{tabular}

Table 1: The results of image correlation processing at various subset values and fixed step value $\Delta X=2$.
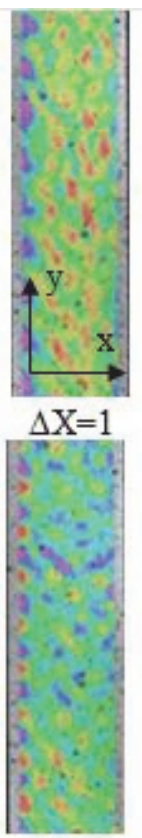

$\Delta \mathrm{X}=1$

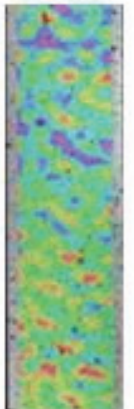

$\Delta \mathrm{X}=1$

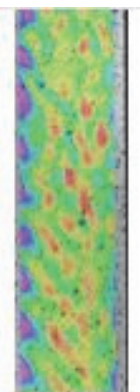

$\Delta \mathrm{X}=\mathbf{2}$

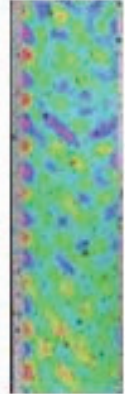

$\Delta \mathrm{X}=\mathbf{2}$

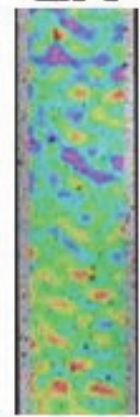

$\Delta \mathrm{X}=\mathbf{2}$

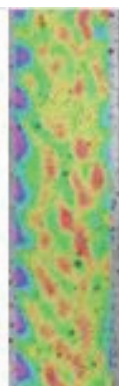

$\Delta \mathrm{X}=3$

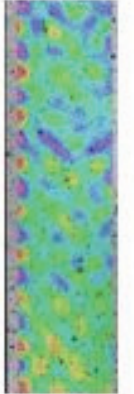

$\Delta \mathrm{X}=3$

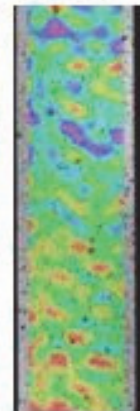

$\Delta \mathrm{X}=3$
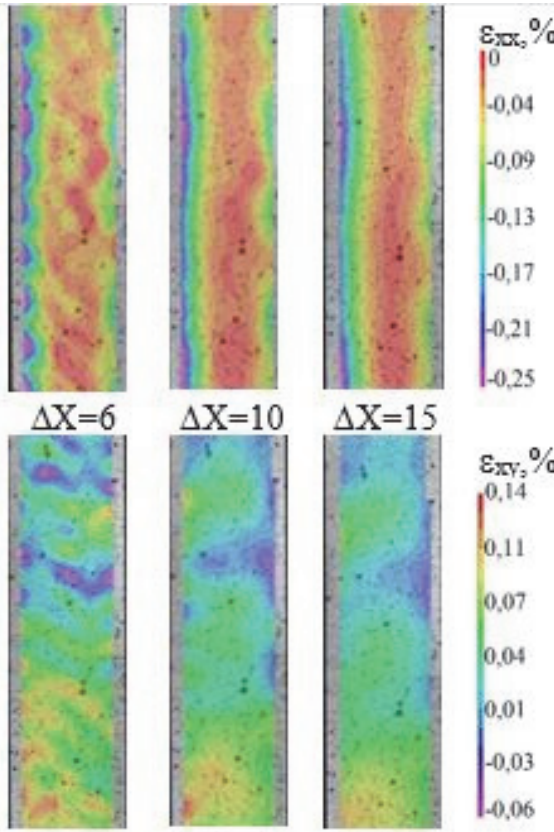

$\Delta \mathrm{X}=10$
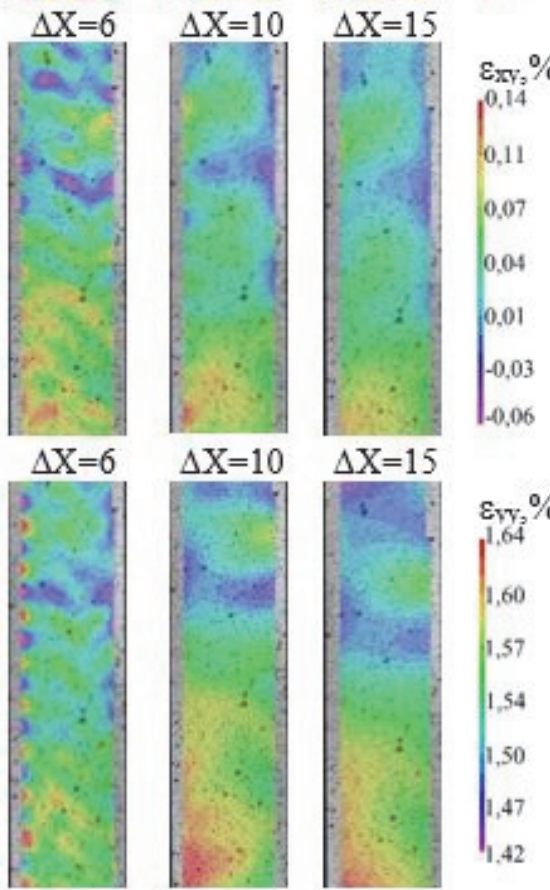

$\Delta \mathrm{X}=6$
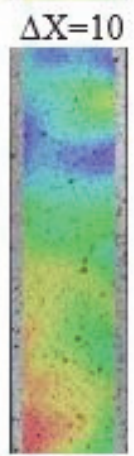

$\Delta \mathrm{X}=15$

$\Delta \mathrm{X}=15$

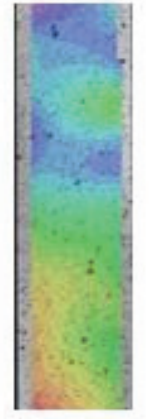

Figure 4: The fields of transversal, shear and longitudinal strain at the fixed value of subset and various step values.

Following the calculation it is observed that the chosen subset size $51 \times 51$ pixels possesses sufficient uniqueness of pixels distribution to provide unique identification of local areas based on the image $A_{\text {mean }}=0.0026, A_{\max }=0.0108$ and $A_{\min }=0.0012$. At smaller size of subset $X<51$ unacceptable values of correlation coefficient $A$ are observed.

After the choice of the suitable subset value, it is necessary to match the step value $\Delta \mathrm{X}$, by which the degree of detail of displacement and deformation fields vary. For this purpose a correlation processing of one image for laminated reinforced 
fiberglass sample at step values at the interval of $\Delta X=1 \div 15$ pixels and at the fixed value of subset $X=51 \times 51$ pixels. As we can see from the Fig. 4 , the smaller the step value $\Delta X=1,2,3$ pixels, the more detailed is the strain field due to the increase of calculation points number. As the parameter $\Delta X=6,10,15$ pixels increases, the non-homogeneity smoothens, the maximal and minimal values, registered on the sample surface, average, the composite material structural features blur and the edge area increases. The non-homogeneous fields of transversal, shear and longitudinal strain at the fixed value of subset $X=51$ and various step values $\Delta X=1 \div 15$ are obtained as a result of the study (Fig. 4).

To assess the structural features of the material, to study the processes of origination and development of defective structures and destruction, to analyze the behavior in stress concentration areas, it is necessary to establish a step size comparable to the size of the structural non-homogeneity $\delta$. Therefore, it has been established that for the studied material, $\Delta X=2$ is a suitable step size because this size makes it possible to take into account the structural features of STEF fiberglass. The fiber bundles size coincides with the size of the field non-homogeneity. The Fig. 5 presents the images of the material structure obtained using a stereo microscope with superimposed non-homogeneous strain fields at a fixed step size $\Delta X=2$.

In view of the fact that the numerical image processing parameters significantly affect the results of building of the displacement and strain fields, when presenting the results obtained using the DIC method, it is necessary to indicate the subset size $X$, the step size $\Delta X$, and the size of the composite material structural element $\delta$.

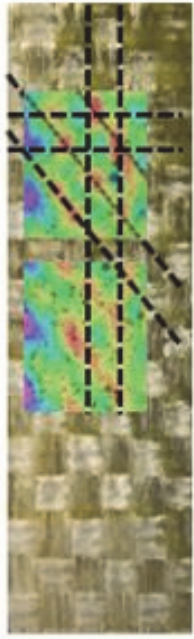

$\varepsilon_{\mathrm{XX}}$

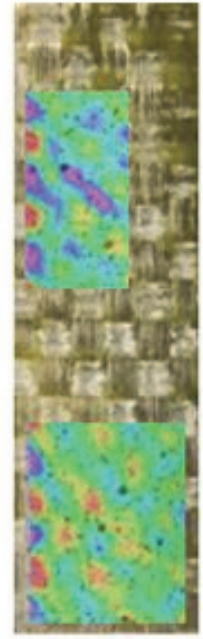

$\varepsilon_{\mathrm{xy}}$
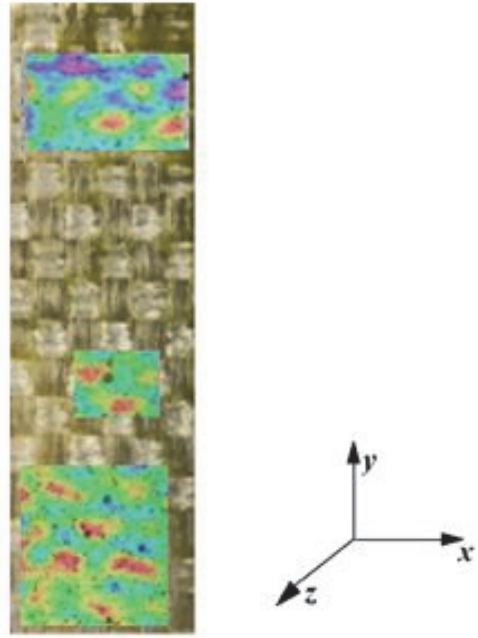

Eyy

Figure 5: The images of the material structure with superimposed non-homogeneous strain fields at a fixed step size.

\section{SCALE LEVELS OF DEFORMATION REGISTRATION}

aking into consideration the size of the structural non-homogeneity of the material, it is possible to affect the scale level of strain registration. To measure the structural deformations, it is necessary to set a smaller step. The structural level $\mathrm{h}$ is the level of structural non-homogeneity. Its scale is smaller than the characteristic size of the inclusion particle or fiber diameter. In this case, deformation changes are recorded on the structural element. The next level is the macroscopic $H$, at which $H>b$ but less than the characteristic size of the product or the distance at which the averaged stresses and strains distinctly change.

Based on the results of the studies conducted, the following recommendations for selection of suitable DIC calculation parameters during the analysis of non-homogeneous deformation fields of composite materials are identified. Choosing the step value $\Delta X$, it is necessary to take into consideration the objective of the study, in particular, when the video system is used as a "virtual extensometer" to determine the general characteristics of the material, when there is no need to take into account the structural features of the material, it is necessary to choose greater values of the step $\Delta X$. The deformation is calculated at the macroscopic level $H$. To assess the structural features of the material, to study the 
processes of origination and development of defective structures and destruction, to analyze the behavior in stress concentration areas, it is necessary to establish a step size $\Delta X$, comparable to the size of the structural non-homogeneity $\delta$. The deformations are calculated at structural level $h$.

An interesting aspect of non-homogeneous strain fields analysis is the location of local strain peaks. For this purpose the Fig. 6 presents the plot of the distribution of longitudinal strains along the width of the sample along a line drawn through the geometric center of the sample perpendicular to the load application. According to Fig. 6 it has been found that the places of greatest deformations are located in the fiber bundles. On the other hand, it has been found that the smallest strain values are located in the narrow regions located mainly at the intersection of longitudinal and transverse fiber beams. These results were obtained using the supplementary video system instrument "line".
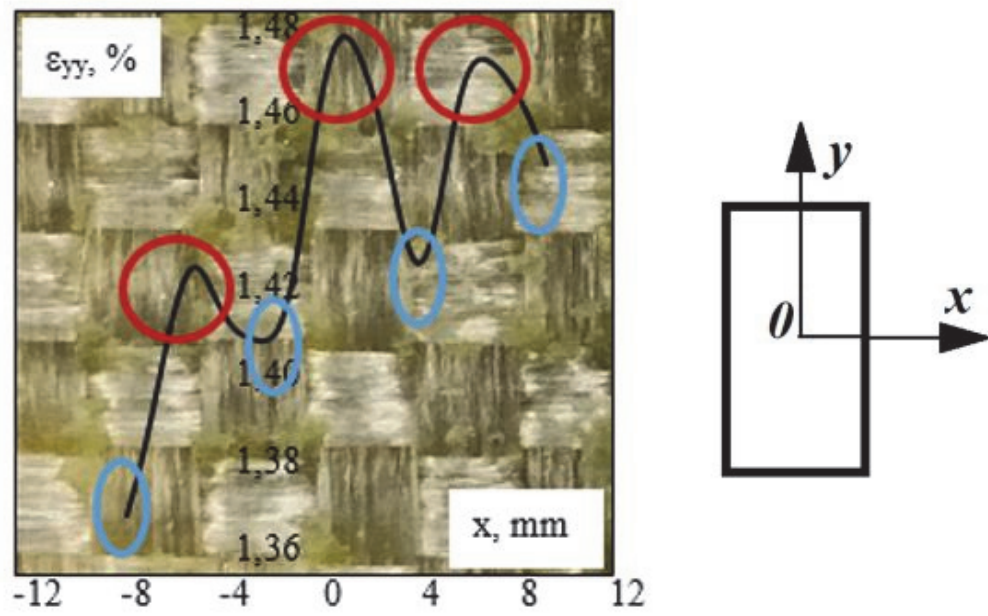

Figure 6: The plot of longitudinal strains superposed on real fiberglass structure.

It is supposed that the strain process in the inner layers of the woven composite is the same as on the surface. To assess the deformations at various scale levels we used a supplementary video system instrument "rectangular area (R)", for which a rectangular site in the form of rectangle was assigned in the specimen working area.

The rectangular area $a \times b \mathrm{~mm}$ is first applied in the center of the specimen working area and is subsequently enlarged (Fig. 7). The schematic picture of the increasing sizes of the "rectangular area" used for local deformation averaging is presented in Fig. 7. The values of axial strain of all the integrity of data points located inside this square, are averaged, and the resulting average value is indicated as $\varepsilon_{\text {local }}$. The error related to calculation of $\varepsilon_{\text {local }}$ is calculated as:

$$
\text { error }=\left(\frac{\varepsilon_{\text {global }}-\varepsilon_{\text {local }}}{\varepsilon_{\text {global }}}\right) \cdot 100
$$

where $\varepsilon_{\text {global }}$ is the total (macroscale) longitudinal deformation obtained along the specimen surface. The Fig. 7 shows the dependence of the of longitudinal deformation mean value $\varepsilon_{\text {local }}$ on the size of the "rectangular area (R)".

The sizes of the "rectangular area $(R)$ " increase proportionally, the number of data points in it increases, and the error is estimated for each corresponding size of the "rectangular area (R)". It can be supposed that the errors value will become smaller at greater sizes of "rectangular areas (R)" "[11,12]. If the established convergence criterion for all cases is $2 \%$, the error is much higher at the smallest size of the "rectangular area (RO)" (Tab. 2).

\begin{tabular}{cccccc}
\hline $\begin{array}{c}\text { Rectangular } \\
\text { area }\end{array}$ & $\mathrm{R} 0$ & $\mathrm{R} 1$ & $\mathrm{R} 2$ & $\mathrm{R} 3$ & $\mathrm{R} 4$ \\
\hline $\begin{array}{c}\text { Area Size, } \mathrm{mm}^{2} \\
\begin{array}{c}\text { Amount of } \\
\text { points, item } \\
\text { error, \% }\end{array}\end{array}$ & 2.86 & 30.50 & 161.84 & 533.01 & 1160.70 \\
\hline
\end{tabular}

Table 2: Characteristics of "rectangular areas (R)". 


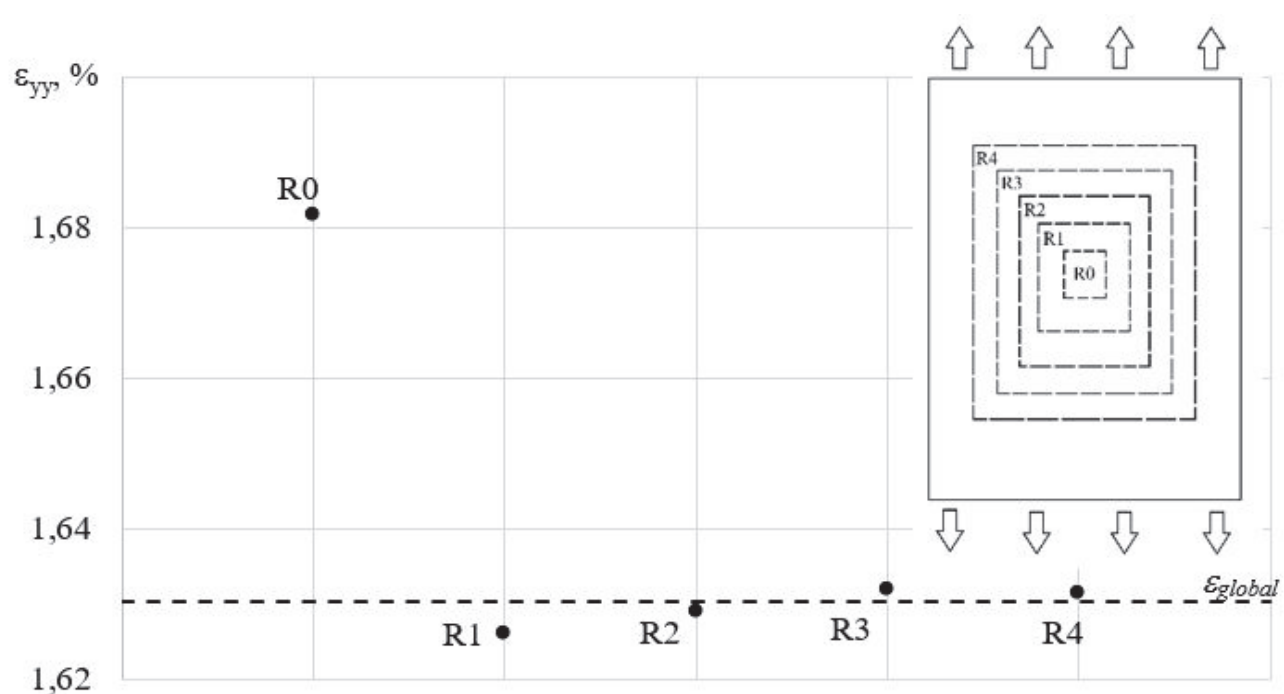

Figure 7: The diagram of dependence of the longitudinal deformation mean value on the "rectangular area" size, schematic picture of increasing size of the "rectangular area" used for local deformation averaging.

It should be noted that the least size of the "rectangular area (R0)" is $2.86 \mathrm{~mm}^{2}$, which is much smaller than the size of the structural element [23] of the material $\delta=16 \mathrm{~mm}^{2}$, but the error in the case surpasses $2 \%$. There is no need to take into consideration the obtained deformation values in the further study.

Considering the next size of the "rectangular area R1" $30.5 \mathrm{~mm}^{2}$, approximately 2 structural elements are taken into consideration, the error value is acceptable, but supplementary results convergence analysis is necessary. Depending of the way the "rectangular area R" of R1 size was applied, the minimal, maximal of mixed strain field areas may be found in the area of the sample deformation identification. If maximal deformations are found in the area, the former will be too high in comparison with the average ones, if they are found in the minimal area, they will be too low.

The sizes of "rectangular areas R2, R3, R4", for which the error is also acceptable, must be theoretically sufficient to present the strain reaction at macroscale. The error in the regions R2, R3 and R4 is the same, it is proposed to use the region R2. The calculation of this area requires the least computational resources. Since the number of calculation points (5580) is the smallest, comparing these three areas.

\section{CONCLUSIONS}

1

he authors have conducted a series of experiments for uniaxial strain on construction fiberglass sample. A series of building the fields for one frame on the surface of laminated reinforced fiberglass at various subset values and at fixed step value was performed to assess the impact of correlation processing on non-homogeneous strain fields. To assess the deformations, the authors used a video system for 3D analysis of displacement and strain fields Vic-3D, based on digital image correlation (DIC) method. Such supplementary video system instruments as "virtual extensometer", "rectangular area" and "line" were used for this purpose.

Therefore, according to the study results it has been found that the selection of correlation analysis parameters should consider the size of structural non-homogeneity of the material; in view of this fact, in become possible to select the scale level of deformation recording. To assess the structural features of the material, to study the processes of origination and development of defective structures and destruction, to analyze the behavior in stress concentration areas, it is necessary to establish a step size comparable to the size of the structural non-homogeneity of the material. In the paper the authors have analyzed the non-homogeneous strain fields on the surface of the composite samples of the studied structure. The options of averaging the deformations in the working area of the tested samples have been analyzed using the supplementary instruments of Vic-3D system. The analysis of displacement and strain fields by digital image correlation data is generally performed along the entire surface of the studied object. The study conducted has proven that the values of composite deformations at smaller sizes differ from the macroscale deformations. 


\section{ACKNOWLEDGEMENTS}

he work is carrying out in Perm National Research Polytechnic University with financial support of grant of President of Russian Federation for government support of young Russian scientists (Grant No MK-1222.2020.8.)

\section{REFERENCES}

[1] Lobanov, D.S., Wildemann, V.E., Spaskova, E.M., Chikhachev, A.I. (2015). Experimental investigation of the defects influence on the composites sandwich panels strength with use digital image correlation and infrared thermography methods. PNRPU Mechanics Bulletin, 4, pp. 159-170. DOI: 10.15593/perm.mech/2015.4.10

[2] Babushkin, A.V., Babushkina, A.V., Strungar, E.M., Staroverov, O.A., Lobanov, D.S., Temerova, M.S., Feklistova, E.V. (2019). Phenomenological characteristics structural features research obtained at fibrous plastics standard tests, Procedia Structural Integrity, 17, pp. 658-665. DOI: 10.1016/j.prostr.2019.08.088.

[3] Fedulov, B.N., Fedorenko, A.N., Kantor, M.M., Lomakin, E.V. (2018). Failure analysis of laminated composites based on degradation parameters, Meccanica, 53(1-2), pp. 359-372. DOI: 10.1007/s11012-017-0735-9.

[4] Rajak, D.K, Pagar, D.D., Kumar, R., Pruncu, C.I. (2019). Recent progress of reinforcement materials: a comprehensive overview of composite materials, Journal of Materials Research and Technology, 8(6), pp. 6354-6374. DOI: $10.1016 /$ j.jmrt.2019.09.068

[5] Panin, S.V., Byakov, A.V., Lyubutin, P.S., Bashkov, O.V., Grenke, V.V., Shakirov, I.V., Khizhnyak, S.A. (2011). Study of Deformation and Fracture Using Data of Acoustic Emission, Correlation of Digital Images and Strain-Gauging, Industrial Laboratory. Material Diagnostics, 77(9), pp. 50-59.

[6] Hadjem-Hamouche, Z., Derrien, K., Héripré, E., Chevalier, J.P. (2018). In-situ experimental and numerical studies of the damage evolution and fracture in a Fe-TiB2 composite, Materials Science and Engineering: A, 724, pp. 594-605. DOI: $10.1016 /$ j.msea.2018.03.108.

[7] Damaskinskaya, E., Panteleev, I., Gafurova, D., Frolov, D. (2018). Defect Structure of Deformed Heterogeneous Materials: Acoustic Emission and X-Ray Microtomography, Procedia Structural Integrity, 13, pp. $298-303$. DOI: $10.1016 /$ j.prostr.2018.12.050.

[8] Mishnaevsky, L., Brondsted, P. (2009). Micromechanical modeling of damage and fracture of unidirectional fiber reinforced composites: a review, Computer Material Science, 44(4), pp. 1351-1359. DOI: $10.1016 /$ j.commatsci.2008.09.004

[9] Ansar, M., Xinwei, W., Chouwei, Z. (2011). Modeling strategies of 3D woven composites: a review, Composite Structure, 93(8), pp. 1947-1963. DOI: 10.1016/j.compstruct.2011.03.010.

[10] Dixit, A., Singh Mali, H. (2013). Modeling techniques for predicting the mechanical properties of woven-fabric textile composites: a review, Mech Composite Material, 49(1), pp. 1-20. DOI: 10.1007/s11029-013-9316-8.

[11] Koohbor, B., Ravindran, S., Kidane, A. (2018). A multiscale experimental approach for correlating global and local deformation response in woven composites, Composite Structures, 194, pp. 328-334.

DOI: $10.1016 /$ j.compstruct.2018.04.016.

[12] Koohbor, B., Ravindran, S., Kidane, A. (2017). Experimental determination of Representative Volume Element (RVE) size in woven composites, Optics and Lasers in Engineering, 90, pp. 59-71.

DOI: $10.1016 /$ j.optlaseng.2016.10.001.

[13] Mehdikhani, M., Aravand, M., Sabuncuoglu, B., Callens, M.G., Lomov, S.V., Gorbatikh, L. (2016). Full-field strain measurements at the micro-scale in fiber-reinforced composites using digital image correlation, Composite Structures, 140, pp. 192-201. DOI: 10.1016/j.compstruct.2015.12.020.

[14] Wildemann, V.E., Spaskova, E.V., Shilova, A.I. (2016). Research of the damage and failure processes of composite materials based on acoustic emission monitoring and method of digital image correlation problems of deformation and fracture in materials and structures, Solid State Phenomena, 243, pp. 163-170.

DOI: $10.4028 /$ www.scientific.net/SSP.243.163.

[15] Tretyakova, T.V., Dushko, A.N., Strungar, E.M., Zubova, E.M., Lobanov, D.S. (2019). Comprehensive analysis of mechanical behavior and fracture processes of specimens of three-dimensional reinforced carbon fiber in tensile tests, PNRPU Mechanics Bulletin, no. 1, pp. 173-183. DOI: 10.15593/perm.mech/2019.1.15. 
[16] Panteleev, I.A., Bayandin, Yu.V., Naimark, O.B. (2016). Spatio-temporal regularities of damage evolution in deformed fiberglass composite laminate by acoustic emission data, Physical Mesomechanics, 19(4), pp. 64-73.

[17] Djabali, A., Toubal, L., Zitoune, R., Rechak, S. (2019). Fatigue damage evolution in thick composite laminates: Combination of X-ray tomography, acoustic emission and digital image correlation, Composites Science and Technology, 183, 107815. DOI: 10.1016/j.jnucmat.2014.08.043.

[18] Nozawa, T., Ozawa, K., Asakura, Y., Kohyama, A., Tanigawa, H. (2014). Evaluation of damage accumulation behavior and strength anisotropy of NITE $\mathrm{SiC} / \mathrm{SiC}$ composites by acoustic emission, digital image correlation and electrical resistivity monitoring, Journal of Nuclear Materials, 455(1-3), pp. 549-553.

DOI: $10.1016 /$ j.jnucmat.2014.08.043.

[19] Sutton, M.A., Orteu, J.-J., Schreier, H. (2009). Image Correlation for Shape, Motion and Deformation Measurements. - University of South Carolina, Columbia, SC, USA, 364 p.

[20] Zheng, O., Mashiwa, N., Furushima, T. (2020) Evaluation of large plastic deformation for metals by a non-contacting technique using digital image correlation with laser speckles, Materials \& Design, 191. DOI: $10.1016 /$ j.matdes.2020.108626.

[21] Park, J., Yoon, S., Kwon, T., Park, K. (2017). Assessment of speckle-pattern quality in digital image correlation based on gray intensity and speckle morphology, Optics and Lasers in Engineering, 91, pp. 62-72. DOI: 10.1016/j.optlaseng.2016.11.001.

[22] Pan, B., Lu, Z., Xie, H. (2010). Mean intensity gradient: An effective global parameter for quality assessment of the speckle patterns used in digital image correlation, Optics and Lasers in Engineering, 48(4), pp 469-477. DOI: 10.1016/j.optlaseng.2009.08.010.

[23] Strungar, E.M., Yankin, A.S., Zubova, E.M. Babushkin, A.V., Dushko, A.N. (2020). Experimental study of shear properties of 3D woven composite using digital image correlation and acoustic emission. Acta Mech. Sin, 36(2). DOI: $10.1007 /$ s10409-019-00921-7. 